\title{
Synthesis and Crystal Structure Determination of [[4-(4-morpholinyl) Phenyl] Methylene] Propanedinitrile from X-ray Powder Diffraction Data
}

\author{
A.M. Moustafa, I. S. Ahmed Farag and A. M. El-Shabiny \\ Solid State Department, Physics Division, National Research Centre, \\ Dokki, Giza, Egypt. \\ Corresponding author E-mail: aishamous@yahoo.com
}

The crystal structure of [[4-(4-Morpholinyl)phenyl] methylene] propanedinitrile has been determined at room temperature from $X$-ray powder diffraction data using the method of simulated annealing as implemented in both of DASH and TOPAS programs. Subsequent Rietveld refinements using the data collected to $1.5 \AA$ resolution yielded $R$-Bragg values of $5.6 \%$. It was found that the compound crystallizes in the monoclinic space group $P 2_{1} / n$, with lattice parameters $a=9.6537(34) \AA, b=19.1766(11) \AA, c=7.3612(15) \AA$ and $\beta=109.218(3)^{\circ}$. The molecules are packed in parallel layers running perpendicular to the $c$-axis with the distance between layers $=4.39 \AA$.

\section{Introduction:}

Arylidenmalononitriles are considered very important class of organic compounds due to not only their ease accessibility but also for highly chemical reactivity. So great attention was directed towards their various analogues for utilization as ideal starting materials towards construction of acyclic or cyclic target organic derivatives. The combination of olifinic linkage conjugated with the nitril groups allows ease nucleophilic attack of different reagents at the $\beta$-carbon of $\alpha, \beta$-unsaturated system which in most cases, accompanied with cyclization affording many promising heterocycles. For example, reaction of arylidenemalonontriles with malonnitrile in the presesnce of sufficient alkoxides gave directly 6-alkoxy-2-amino-4-aryl-3,5-pyridinedicarbonitriles[1]. Similarly, reaction of arylidenemalnonitriles with either activated methyl "exemplified by (un)substituted acetophenones" or methylene containing compounds "exemplified by 1-indonone, $\alpha$-tetralone, 1-benzosuberone, 4chromanone, 4- thiocromanone and 1-benzothiepin-s-one" in the presence of sufficient alkoxides gave exclusively, 2 -alkoxy- $\beta$-pyridinecarbonitriles and 
their fused systems [1-6]. Many of the prepared 2-alkoxy-3pyridinecarbonitriles exhibit considerable fluorecocence properties with recognizable quantum yields and could be applicable to non wood fiber materials producing special paper types (security paper)[2]. Additionally, drylidenemalanonitriles easly reacted with active methylene containing heterocycles "exemplified by pyrazol-s-ones, 2-thiohydations, oxazolin- $\mathrm{s}(4 \mathrm{H})$-ones, thiazolinones" affording different fused heterocyclic systems [7-13].

Herein the three dimensional structure of [4-(4-Morpholinyl) phenyl]methylene]propanedinitrile is reported from high resolution powder diffraction data. It is worth mentions that this compound does not crystallize in the form of single crystal.

\section{Experimental:}

\subsection{Synthesis :}

A solution of 4-fluorobenzylidenemalonnitrile (1) $(1.7 \mathrm{~g}, 10 \mathrm{mmol})$ and morpholine (2) (12mmol) in dioxane $(20 \mathrm{ml})$ was heated under reflux for $12 \mathrm{~h}$. The reaction mixture was stored overnight at room temperature [1]. The solid formed was collected and crystallized from ethanol to give (3) as orange yellow powder $(1.3 \mathrm{~g}, 54.4 \%)$; m.p. $191-193^{\circ} \mathrm{C}$. Anal. Calcd. For $\mathrm{C}_{14} \mathrm{H}_{13} \mathrm{~N}_{3} \mathrm{O}$ (239.279): C 70.28, H 5.48, N 17.56; found: C 70.23, H 5.48, N $17.67 \%$. ${ }^{1} \mathrm{H}-$ NMR (CDCl3): $\delta 3.43$ [t, 4H, N( $\left.\left(\mathrm{CH}_{2}\right)_{2}, J=5 \mathrm{~Hz}\right] ; 3.86\left[\mathrm{t}, 4 \mathrm{H}, \mathrm{O}\left(\mathrm{CH}_{2}\right)_{2}, J=5\right.$ $\mathrm{Hz}$; 7.51 (s, $1 \mathrm{H},-\mathrm{CH}=) ; 6.88(\mathrm{~d}, 2 \mathrm{H}$, arom. H-3 \& H-5, J=9.1 Hz); $7.84(\mathrm{~d}$, 2H, arom. H-2 \& H-6, J = 8.9 Hz). IR: v $2218 \mathrm{~cm}-1(\mathrm{C} \equiv \mathrm{N}) ; 1611(\mathrm{C}=\mathrm{C})$.

\subsection{X-ray Powder Data Collection:}

High resolution X-ray powder diffraction patterns of [[4-(4-Morpholinyl) phenyl]methylene]propanedinitrile were recorded at room temperature on a computer controlled laboratory powder diffractometer (D-8, Bruker, using the monochromatic $\mathrm{Cu}-\mathrm{K}-\alpha_{1}$ radiation from primary $\mathrm{Ge}(111)$-Johannson-type monochromator; Våntag-1 position sensitive detector (PSD) with an opening angle of $6^{\circ}$ ) in Debye-Scherrer geometry with the samples sealed in borosilicate glass capillaries of $0.5 \mathrm{~mm}$ diameter (Hilgenberg glass No. 50). Data were taken in steps of $0.009^{\circ} 2 \theta$ from $2.0-62.0^{\circ} 2 \theta$ for $0.05^{\circ} /$ minute (Fig. 1). The samples were spun during measurement for better particle statistics. 


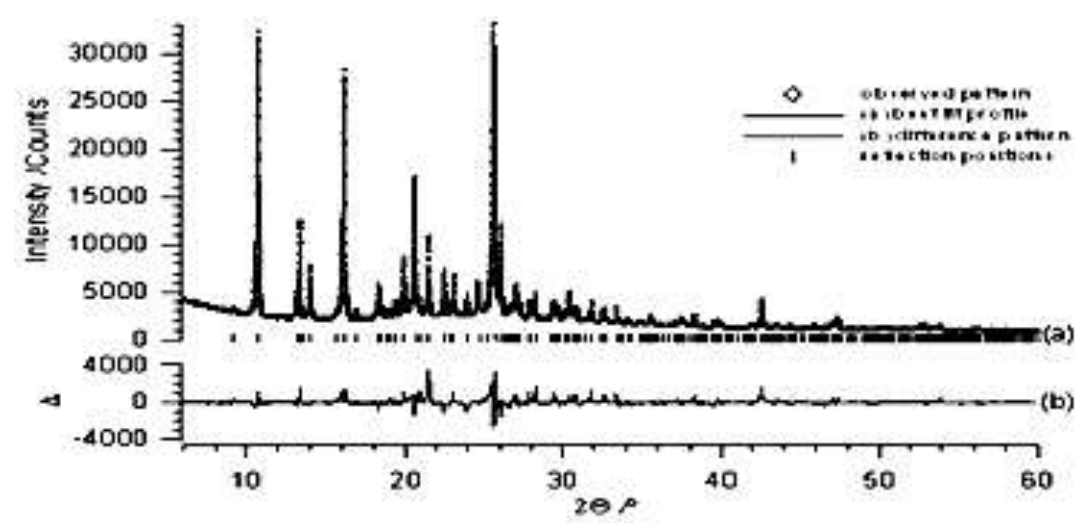

Fig. (1): Scattered $\mathrm{X}$-ray intensities of the compound $\mathrm{C}_{14} \mathrm{H}_{13} \mathrm{~N}_{3} \mathrm{O}$ at ambient conditions as a function of diffraction angle $2 \theta$. The observed pattern (diamonds), the best Rietveld fit profiles (line) and the difference curve between the observed and the calculated profiles (below) are shown.

\subsection{Crystal Structure Determination:}

The program DASH [14] was employed for structure solution, the powder pattern was truncated to a real-space resolution with $1.6144 \AA$. The background was initially subtracted with a Robust Bayesian analysis [15]. Accurate peak positions for indexing were obtained by fitting 20 manually selected peaks with an asymmetry-corrected Voigt function. Indexing with the program DICVOL91 [16] returned a monoclinic unit cell with satisfactory figure of merit $[\mathrm{M} 20=40$ and F20=74], the space group could be determined unambiguously as $\mathrm{P} 21 / \mathrm{n}$ from the observed extinction rules. The number of formula units per unit cell was determined as $Z=4$ giving single molecule per asymmetric unit cell.

The integrated intensities were extracted from a Pawley [17] type refinement, using the program DASH. The peak profile was modeled by the Voigt function in combination with a special function that accounts for the asymmetry due to axial divergence [18]. The background was included in the refinement process using two order Chebyshev polynomials. The covariance matrix of the Pawley fit, which describe the degree of correlation between the individual intensities of neighboring reflections, was actively used in calculation of the agreement level between the measured intensities and those of the trial structures after each simulated annealing. It was therefore not necessary to include the entire powder pattern in the simulated annealing procedure, which considerably decreased the computing time needed for each cycle. The Pawley fit for the investigated compound with 319 reflections in the angular range 5-57.0 $2 \theta$ (5939 data points) led to profile values of Rwp 15.7, 
Rexpected 5.63 and Pawely $\chi^{2}$ 7.78. After obtaining a good profile fit, the molecular structure had been done using the DASH program, three input files were needed for solving the molecular structure (i) a description of the connectivity of the molecules including possible torsion angles, (ii) a list of diffraction peak intensities, (iii) and a list of parameters to be varied and their ranges for the simulated annealing runs. The input file for the molecule was constructed using the Chemskitch Program [19], which creates and visualizes three-dimensional molecular structures. For the definition of the connectivity between the atoms within the molecule, the Z-matrix notation was used, which allows for the description of the entire molecule and its intramolecular degrees of freedom by employing interatomic distances, angles and dihedral angles. All intramolecular angles and distances were kept fixed at standard values derived from an optimization in Chemsketch.

For solving the crystal structure of investigated compound six external degrees of freedom were subjected to global optimization; three translations and three rotations. In addition, several internal degrees of freedom were included in the structure determination process (four torsion angles). All degrees of freedom were assigned random values at the start of the simulated annealing. The maximum number of moves per run was set to $1.00 \times 10^{7}$, the default values of the starting temperature for the simulated annealing (SA) run were used. The best SA solution had a favorable $\chi 2(\mathrm{SA}) / \chi 2$ (Pawely) ratio of 3.7 and a chemically reasonable packing arrangement, with no significant misfit to the diffraction data.

In order to perform Rietveld refinement $[20,21]$ of the entire powder pattern, the program TOPAS 3.0 (Bruker-AXS) was used [22]. The peak profile and precise lattice parameters of the powder diffraction patterns of investigated compound was determined by Le-Bail fit [23] using the fundamental parameter (FP) approach of TOPAS [24].

Due to the fact that the geometry of the Vantag-1 PSD is not fully characterized by FP's, fine tuning of the available parameters was performed by using refined values of the FP from a precise measurement of the NIST line profile standard SRM 660a (LaB6) in a $0.1 \mathrm{~mm}$ capillary over the full two theta range of the diffractometer. For the description of the apparent anisotropic peak broadening, the phenomenological microstrain model from Stephens [25] was coded in a TOPAS macro and 6 parameters could be refined successfully, considerably lowering the weighted profile agreement factors. For the description of the molecules, z-matrices were created using the z-matrix editor of TOPAS. During the SA runs using the standard SA macro of TOPAS, the peak profile parameters were kept fixed, while all external as well as the internal parameters of the connected rings were subjected to global 
optimization. In addition an isotropic temperature factor B, restricted to values between 1 and 5 and the parameters of the background polynomial were refined after each SA cycle. No anti-bumping penalties were defined. After about 6 hours, a reasonable structural model was found for the investigated compound. It should be noted that no difference in the atomic positions beyond 3 sigma was found for the structure solutions of the compound obtained by the DASH and the TOPAS programs. For the final Rietveld refinements of investigated compound (Fig. 1) and all profile and lattice parameters were released. In addition, soft constraints were employed for all bond lengths and angles with the allowed deviations limited to a maximum of $0.01 \AA$ and $0.8^{\circ}$, respectively. Final agreement factors (R-values) are listed in Table (1). The atomic coordinates are given in Table (2) and a selection of intermolecular distances and angles is given in Table (3). The molecular structure and atom-numbering scheme of the investigated compound are shown in Fig. (2). The crystallographic data has been deposited at Cambridge Structural Data Base under CCDC \# 776852.

Table 1: Crystallographic data for the compound $\mathrm{C}_{14} \mathrm{H}_{13} \mathrm{~N}_{3} \mathrm{O}$.

\begin{tabular}{|l|l|}
\hline Temperature $(\mathrm{K})$ & 298 \\
\hline Chemical formula & $\mathrm{C}_{14} \mathrm{H}_{13} \mathrm{~N}_{3} \mathrm{O}$ \\
\hline Formula weight $(\mathrm{g} / \mathrm{mol})$ & 239.278 \\
\hline system & Monoclinic \\
\hline Space group & $\mathrm{P}{ }_{1} / \mathrm{n}$ \\
\hline $\mathrm{Z}$ & 4 \\
\hline$a(\AA)$ & $9.6537(34)$ \\
\hline$b(\AA)$ & $19.1766(11)$ \\
\hline $\mathrm{c}(\AA)$ & $7.3612(15)$ \\
\hline$\beta\left({ }^{\circ}\right)$ & $109.218(3)$ \\
\hline $\mathrm{V}(\AA)$ & $1286.797(91)$ \\
\hline $\mathrm{D}-\mathrm{calc}\left(\mathrm{g} / \mathrm{cm}^{3}\right)$ & $1.23501 \mathrm{~g} / \mathrm{cm}^{3}$ \\
\hline Wavelength $(\AA)$ & 1.54059 \\
\hline${ }^{*} \mathrm{R}-\mathrm{p}(\%)$ & 6.4 \\
\hline${ }^{*} \mathrm{R}-\mathrm{wp}(\%)$ & 8.1 \\
\hline${ }^{*} \mathrm{R}-\mathrm{F}^{2}(\%)$ & 5.6 \\
\hline Starting angle $\left({ }^{\circ} 2 \theta\right)$ & 2 \\
\hline Final angle $\left({ }^{\circ} 2 \theta\right)$ & 60 \\
\hline Step width $\left({ }^{\circ} 2 \theta\right)$ & 0.0086 \\
\hline Time/step $($ sec $)$ & 12 \\
\hline No. of reflections & 375 \\
\hline Number of atoms & 31 \\
\hline No. of variables & 123 \\
\hline & \\
\hline
\end{tabular}


(**Rp, Rwp, and $\mathrm{R}_{\mathrm{F}}{ }^{2}$ as defined in TOPAS (Bruker AXS)).

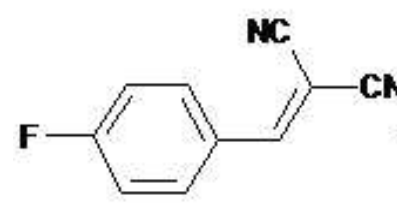

(1)

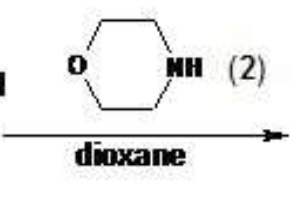

$\checkmark N$

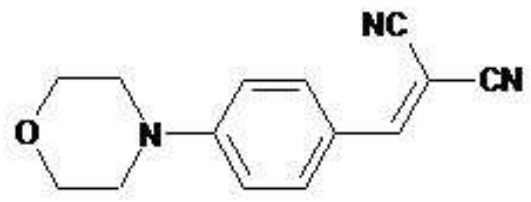

(3)

Scheme 1

Table (2): The atomic coordinate of non hydrogen atoms of the compound $\mathrm{C}_{14} \mathrm{H}_{13} \mathrm{~N}_{3} \mathrm{O}$ at ambient conditions. The temperature factors have been constrained to be equal for all atoms of the molecule.

\begin{tabular}{|c|c|c|c|c|c|}
\hline Atom & Site & $\mathrm{x} / \mathrm{a}$ & $\mathrm{y} / \mathrm{b}$ & $\mathrm{z} / \mathrm{c}$ & $\mathrm{B}_{\mathrm{eq}}(\AA)$ \\
\hline $\mathrm{N} 1$ & $4 \mathrm{e}$ & $-0.2226(5)$ & $0.7008(2)$ & $0.1854(5)$ & $4.0(4)$ \\
\hline $\mathrm{C} 2$ & $4 \mathrm{e}$ & $-0.1654(5)$ & $0.7677(3)$ & $0.1439(5)$ & $4.0(4)$ \\
\hline $\mathrm{C} 3$ & $4 \mathrm{e}$ & $-0.3820(6)$ & $0.7024(2)$ & $0.1504(5)$ & $4.0(4)$ \\
\hline $\mathrm{C} 4$ & $4 \mathrm{e}$ & $-0.2166(5)$ & $0.8280(2)$ & $0.2475(6)$ & $4.0(4)$ \\
\hline $\mathrm{C} 5$ & $4 \mathrm{e}$ & $-0.4219(5)$ & $0.7654(2)$ & $0.2514(5)$ & $4.0(4)$ \\
\hline O6 & $4 \mathrm{e}$ & $-0.3724(3)$ & $0.8281(1)$ & $0.1905(3)$ & $4.0(4)$ \\
\hline $\mathrm{C} 7$ & $4 \mathrm{e}$ & $0.0178(4)$ & $0.5132(3)$ & $0.2436(5)$ & $4.0(4)$ \\
\hline $\mathrm{C} 8$ & $4 \mathrm{e}$ & $-0.1213(5)$ & $0.5135(3)$ & $0.2657(6)$ & $4.0(4)$ \\
\hline $\mathrm{C} 9$ & $4 \mathrm{e}$ & $0.0734(4)$ & $0.5758(2)$ & $0.2025(6)$ & $4.0(4)$ \\
\hline $\mathrm{C} 10$ & $4 \mathrm{e}$ & $-0.2008(5)$ & $0.5761(2)$ & $0.2461(7)$ & $4.0(4)$ \\
\hline $\mathrm{C} 11$ & $4 \mathrm{e}$ & $-0.0052(4)$ & $0.6374(2)$ & $0.1829(5)$ & $4.0(4)$ \\
\hline $\mathrm{C} 12$ & $4 \mathrm{e}$ & $-0.1425(5)$ & $0.6378(2)$ & $0.2049(6)$ & $4.0(4)$ \\
\hline $\mathrm{C} 13$ & $4 \mathrm{e}$ & $0.1022(4)$ & $0.4463(2)$ & $0.2657(5)$ & $4.0(4)$ \\
\hline $\mathrm{C} 14$ & $4 \mathrm{e}$ & $0.2426(4)$ & $0.4433(2)$ & $0.2706(5)$ & $4.0(4)$ \\
\hline $\mathrm{C} 15$ & $4 \mathrm{e}$ & $0.3261(4)$ & $0.5086(1)$ & $0.2493(6)$ & $4.0(4)$ \\
\hline $\mathrm{N} 16$ & $4 \mathrm{e}$ & $0.3896(2)$ & $0.5581(1)$ & $0.2328(3)$ & $4.0(4)$ \\
\hline $\mathrm{C} 17$ & $4 \mathrm{e}$ & $0.3197(4)$ & $0.3732(2)$ & $0.2985(6)$ & $4.0(4)$ \\
\hline $\mathrm{N} 18$ & $4 \mathrm{e}$ & $0.3786(3)$ & $0.3196(1)$ & $0.3198(5)$ & $4.0(4)$ \\
\hline
\end{tabular}


Table 3: Selected geometrical values $(\AA),{ }^{\circ}$.

\begin{tabular}{|l|l|}
\hline C7-C9 & $1.388(7)$ \\
\hline C9-C11 & $1.386(5)$ \\
\hline C11-C12 & $1.387(7)$ \\
\hline C12-C10 & $1.386(6)$ \\
\hline C14-C15 & $1.525(5)$ \\
\hline C14-C17 & $1.517(5)$ \\
\hline C7-C13 & $1.500(6)$ \\
\hline N1-C2-C4 & $110.3(4)$ \\
\hline C2-C4-O6 & $109.4(3)$ \\
\hline C4-O6-C5 & $109.8(3)$ \\
\hline O6-C5-C3 & $110.5(3)$ \\
\hline C3-N1-C2 & $112.8(4)$ \\
\hline N1-C2-C4 & $110.3(4)$ \\
\hline C7-C13-C14 & $123.1(4)$ \\
\hline C14-C17-C18 & $180.0(4)$ \\
\hline C14-C15-C16 & $179.8(3)$ \\
\hline
\end{tabular}

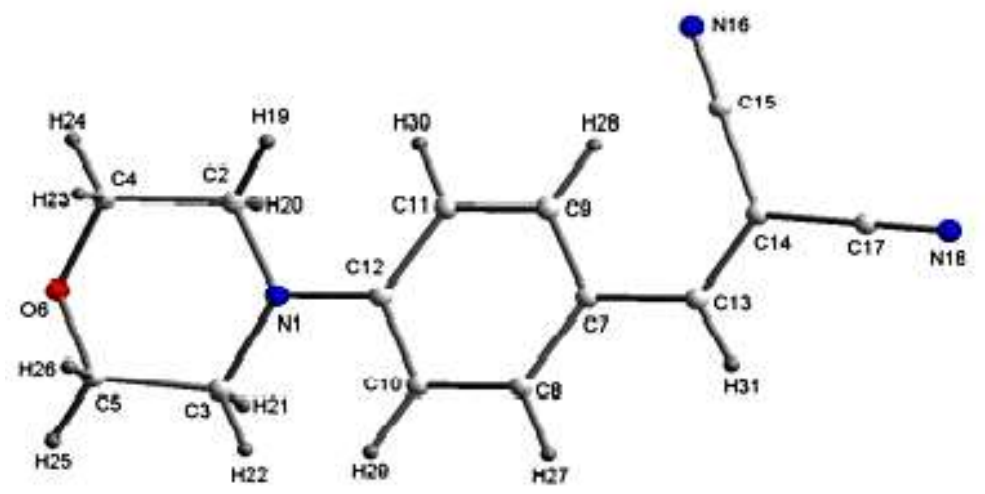

Fig. (2): Molecular structure of $\mathrm{C}_{14} \mathrm{H}_{13} \mathrm{~N}_{3} \mathrm{O}$.

\section{Results and Discussion:}

The asymmetric unit of the investigated compound shown in Fig.(2), comprises one complete molecule located on a general position and thus 31 independent atoms for this compound. The investigated compound consists of aromatic phenyl ring attached from one side to morpholinyl ring and in the para-position to methylene group. The morpholinyl ring takes the shape of chair 
configuration, the perpendicular distance of the two chair atoms O6 and N1 from the plane of the other four atoms of the six membered morpholinyl ring are $0.689(2) \AA$ and $-0.591(4) \AA$ respectively. The $\mathrm{C}_{\mathrm{sp} 3}-\mathrm{N}_{\mathrm{sp} 3}$ bonds are 1.468(7) $\AA$ and 1.474(7) $\AA$, the $\mathrm{C}_{\mathrm{sp} 3}-\mathrm{C}_{\mathrm{sp} 3}$ bonds are 1.553(7) $\AA$ and 1.533(6) $\AA$ while the $\mathrm{C}_{\mathrm{sp} 3} \mathrm{O}$ bonds are $1.422(5) \AA$ and $1.420(5) \AA$, the average values of the bond angles if this ring $=110.51^{\circ}$. The average values of the bond lengths of the phenyl ring=1.393(6) $\AA$ indicate that they are partial double bonds. The bond length $\mathrm{N} 1-\mathrm{C} 12=1.416(6) \AA$ is shortened single bond and this may be to compensate the heavy substitution at $\mathrm{C} 12$. The values of the bond length $\mathrm{C} 7-\mathrm{C} 13=1.500(6) \AA$ is shorter than the ideal value of $\mathrm{C}-\mathrm{C}$ single bond and this may be due to the substitution effect at $\mathrm{C} 13$ moreover the bond angle C7-C13-C14 $=123.1^{\circ}$ is distorted from ideal $120^{\circ}$ which may be due to the heavy substitution at $\mathrm{C} 14$. The two cyanide groups attained a shortened triple bond $\mathrm{C} 15-\mathrm{N} 16=1.158(4) \AA, \mathrm{C} 17-\mathrm{N} 18=1.160(4) \AA$, and these bond lengths agree with that reported by many authors [26-28]. The dihedral angle between the least square planes passing by both of the morpholinyl ring and the phenyl ring is equal to $34.29^{\circ}$. The values of the torsion angles C9-C7-C13-C14 and C8-C7-C13-C14 are $8.3(6)^{\circ}$ and $171.4(4)^{\circ}$ which means that the methelyne group is nearly coplanar with the phenyl ring.

The packing diagram of the investigated compound is shown in Fig.(3), where the hydrogen atoms are omitted for clarity, view along $b$ axis. The figure reveals that the molecules are packed in parallel layers running nearly perpendicular to the c-axis [the shortest unit cell axis] with the distance between layers $=4.39 \AA$ which is nearly $1 / 4 \mathrm{~b}$ axis.

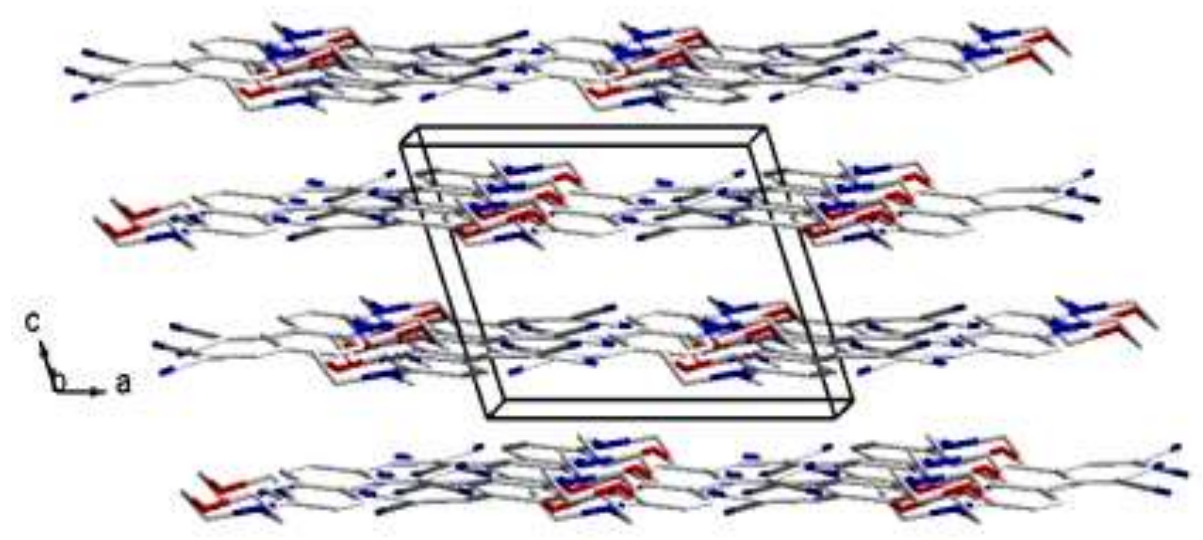

Fig. (3): The packing diagram of the compound $\mathrm{C}_{14} \mathrm{H}_{13} \mathrm{~N}_{3} \mathrm{O}$.

Figure (4) represents the packing diagram of the investigated compound, view along [001] central projection camera distance $50 \mathrm{~cm}$, showing a net 
work of C-H...N and C-H...O intermolecular contacts (dashed lines), stabilizes the structure in different symmetry related codes some of them listed in Table (4).

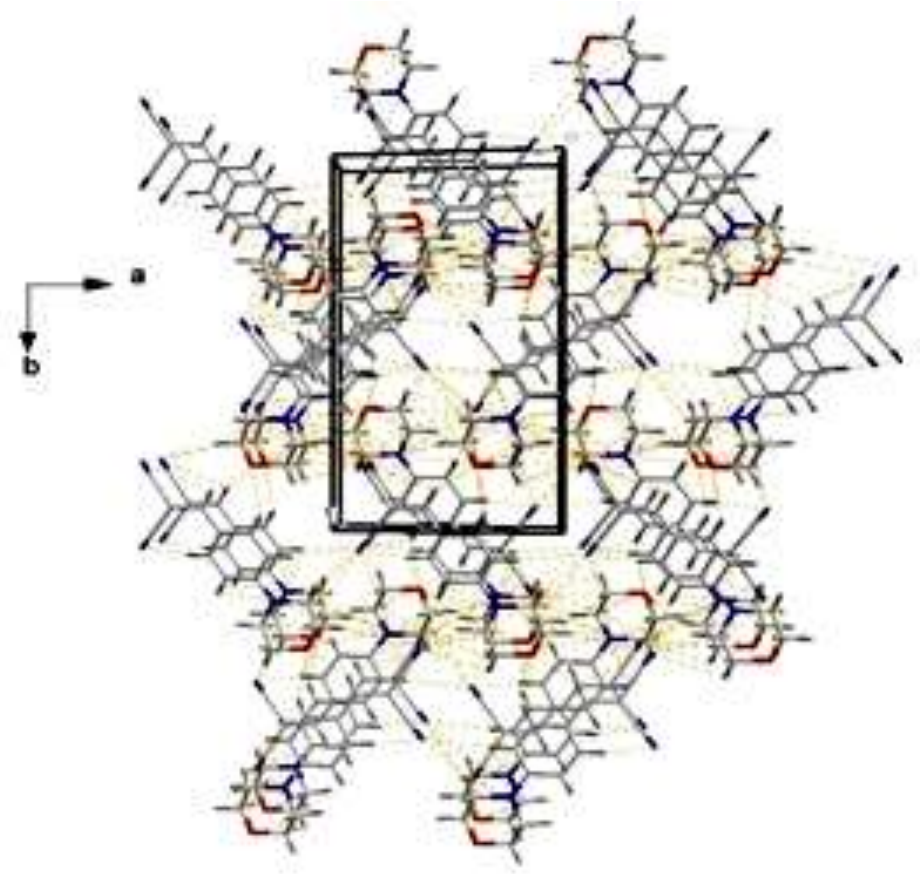

Fig. (4): The packing diagram of the compound $\mathrm{C}_{14} \mathrm{H}_{13} \mathrm{~N}_{3} \mathrm{O}$, view along [001] direction.

Table (4): Selection of intermolecular contact of the compound $\mathrm{C}_{14} \mathrm{H}_{13} \mathrm{~N}_{3} \mathrm{O}$ at $298 \mathrm{~K}$. (symmetry operation $1 / 2-\mathrm{x}, 1 / 2+\mathrm{y}, 1 / 2-\mathrm{Z} ;-1 / 2-\mathrm{x}, 1 / 2+\mathrm{y}, 1 / 2-\mathrm{z}$ ).

\begin{tabular}{|c|c|c|c|c|}
\hline D-H...A & D-H $(\AA)$ & H...A $(\AA)$ & D....A $(\AA)$ & $\mathrm{D}-\mathrm{H} \ldots \mathrm{A}^{\circ}$ \\
\hline C2-H19....N18 & $0.99(3)$ & $2.03(3)$ & $2.871(6)$ & $140(2)$ \\
\hline C13-H31...O6 & $0.99(2)$ & $2.35(2)$ & $3.261(5)$ & 152(2) \\
\hline
\end{tabular}

\section{References:}

1. N. Mishriky, F. M. Asaad, Y. A. Ibrahim, A. S.Girgis, Recl. Trav. Chim. Pays-Bas, 113, 35 (1994).

2. A. H. Basta, A. S. Girgis, H. El-Saied, Dyes \& Pigments, 54, 1 (2002).

3. N. Mishriky, F. M. Asaad, Y. A. Ibrahim., A. S. Girgis, J. Chem. Research (S) 316 (1997).

4. N. Mishriky, Y. A. Ibrahim, A. S. Girgis, N.G. Fawzy, Pharmazie, 55, 269 (2000). 
5. A. S. Girgis, I. S. Ahmed Farag, Z. Naturforsch. 58b, 698 (2003).

6. A. S. Girgis, N. Mishriky, M. Ellithey, H. M. Hosni, H. Farag, Bioorg. Med. Chem. 15, 2403 (2007).

7. N. Mishriky, A. S. Girgis, F. M. Assad, Y. A. Ibrahim, U. I. Sobieh, N. G. Fawzy, Boll. Chim Farmac, 140, 129 (2001).

8. N.Martin-Leon, M. Quinteiro, C. Seoone, J. L. Soto, Liebigs Ann. Chem., 101 (1990).

9. M. I. Younes, A. H.Atta, S. A. M. Metwally, M. H. Elnagdi, Gazz. Chim. Ital. 121, 185 (1991).

10. M. A. Abdelaziz, H. H. Moharram, S. A. Esawy, A. A. Mohamed, Phosphours, Sulfur Silicon Relat Elem., 48, 269 (1990).

11. Z. E. Kandeel, A. M. Farag, A. M. Negm, A. K. Khalafalla, M. A. M. Rasslan, M. H. El-nagdi, J. Chem.Res., (S) 416 (1994).

12. R. M. Mohareb, H. F. Zohdi, W. W. Wardakhan, Monatsh. Chem., 126, 1391 (1995).

13. S. A. Osman, G. E. H. Elgemeie, G. A. Nawar, M. H. El-Nagdi, Monatsh. Chem., 117, 105 (1986).

14. W. I. F. David, K. Shankland, J van de Streek, E. Pidcock, W. D. S. Motherwel, J. C. Cole, J. Appl. Cryst. 39, 910 (2006).

15. W. I. F. David, D. S. Sivia, J. Appl. Cryst., 34, 318 (2001).

16. A. Boultif, D.Loüer, J. Appl. Cryst., 24, 987 (1991).

17. G. S. Pawley, J. Appl. Cryst., 14, 357 (1981).

18. L. W. Finger, D. E.Cox, A. P. Jephcoat, J. Appl. Cryst. 27, 892 (1994).

19. $\mathrm{ACD} /$ ChemSketch, freeware version, Advanced Chemistry Development Inc., http://www.acdlabs.com.

20. H. M. Rietveld, Acta Cryst., 22, 151 (1967).

21. H. M. Rietveld, J. Appl. Cryst., 2, 65 (1969).

22. A. A. Coelho, J. Appl. Cryst., 33, 899 (2000).

23. A. Le Bail, H. Duroy, J. L. Fourquet, Mater. Res. Bull., 23, 447 (1988).

24. R. W. Cheary, A. A. Coelho, J. P. Cline, J. Res. Natl. Inst. Stand. Technol., 109, 1 (2004).

25. P. W.Stephens, R. E. Dinnebier,. R. V. Dreele, S. Jelonek, J. Sieler, J. Appl. Cryst., 32, 761 (1999).

26. M. Liang, H. Yennawar, M. Maroncelli, Acta Cryst., E65, O1687 (2009).

27. A. M. Asiria, Ng S.Weng, Acta Cryst., E65, O761 (2009).

28. G. J. Gainsford, M. D. H. Bhuiyan, A. J. Kay, Acta Cryst., C64, O616 (2008). 